\title{
$\mathbb{A}$ Economics Bulletin
}

Volume 28, Issue 12

Research Announcement

\section{Cross-border shopping in a federal economy}

\author{
Vander Lucas \\ IRES/UCL and Universidade Catolica de Brasilia, Brazil.
}

\begin{abstract}
The purpose of this paper is to consider an economy that incorporates cross-border shopping and where the different levels of government are concerned with the well-being of their citizens. We assume a federal economy with a central government and two regions with specific characteristics. Two kinds of externalities, horizontal and vertical, arise and we show the possibilities of internalising them. With the governments of symmetric regions behaving as Nash players, they would optimally set their tax rates and replicate the unitary nation optimum. Finally, we show how the central government as a Stackelberg leader can adjust its fiscal instruments so that the tax externalities are also internalised.
\end{abstract}

\author{
Published as a working paper in http://www.ires.ucl.ac.be/DP/Biblio_html/2002-18.html \\ Paper is available at URL: \\ Vander Lucas \\ IRES/UCL and Universidade Catolica de Brasilia, Brazil. \\ lucas@ires.ucl.ac.be \\ Place Montesquieu, 3. \\ Louvain la Neuve, B-1348, Belgium \\ 0032(0)10 473993(Phone) \\ 0032(0)10 473945(Fax)
}

Citation: Vander Lucas, (2002) "Cross-border shopping in a federal economy", Economics Bulletin, Vol. 28 no.12 p.A1.

Submitted: December 05, 2002 Published: December 05, 2002.

URL: http://www.accessecon.com/pubs/EB/2002/Volume28/EB-02AA0019A.pdf 